\title{
Moxibustion for Chronic Pelvic Inflammatory Disease:A systematic review and meta-analysis
}

\author{
Fanghui Hua ${ }^{1}$, Jun Xiong ${ }^{1}$, Shouqiang Huang ${ }^{1}$, and Jie Xiang ${ }^{1}$ \\ ${ }^{1}$ Affiliation not available
}

March 28, 2021

\begin{abstract}
Background: This study was performed to strictly evaluate the quality of RCTs and thus test the effect of moxibustion on CPID. Methods: Seven databases (PubMed, Cochrane Library, Embase, China National Knowledge Infrastructure, WangFang Database, Chinese Scientific Journal Database, Chinese Biomedical Literatures Database were reviewed for RCTs on CPID treated by moxibustion up to September 2020. Methodological quality and evidence level was assessed on the basis of the RoB tool from Cochrane collaboration and the GRADE instrument, respectively. RevMan5.4.1 and Stata 12.0 software were used for further meta-analysis.Results: A total of $17 \mathrm{RCTs}$ were included (1315 participants, 515 treated by moxibustion and 515 treated by control therapy). The meta-analysis showed that, in comparison to control group, moxibustion had a higher total effective rate $(\mathrm{RR}=1.21 ; 95 \% \mathrm{CI}[1.31,1.29] ; \mathrm{P}=0.007 ; \mathrm{I} 2=53 \%)$; and lower total symptom score $(\mathrm{MD}=-3.72 ; 95 \% \mathrm{CI}$ $[-4.38,-3.06] ; \mathrm{P}=0.02 ; \mathrm{I} 2=66 \%)$. As for the total sign score, the participants treated by moxibustion had lower scores than those treated by control therapy(SMD $=-0.72 ; 95 \%$ CI $[-1.07,-0.37] ; \mathrm{P}=0.36 ; \mathrm{I} 2=0 \%$ ). For the VAS score, pelvic fluid and inflammatory factor level, only one trial showed that there was a significant effect, respectively. Conclusions: This study shows that moxibustion is more effective and safe for CPID. The findings we obtained must be interpreted with caution due to universal low quality and low evidence level of the eligible trials.
\end{abstract}

\section{Hosted file}

Main Document_20210310214530.pdf available at https://authorea.com/users/404495/articles/ 515662-moxibustion-for-chronic-pelvic-inflammatory-disease-a-systematic-review-and-metaanalysis

\section{Hosted file}

Figure.pdf available at https://authorea.com/users/404495/articles/515662-moxibustion-forchronic-pelvic-inflammatory-disease-a-systematic-review-and-meta-analysis 